\title{
Cost-free feed-in tariffs for renewable energy deployment in Spain
}

\author{
Cristobal Gallego-Castillo \\ Marta Victoria
}

A B S T R A C T

\begin{abstract}
Feed-in-tariff (FIT) schemes have been widely employed to promote renewable energy deployment. While FITs may be perceived by consumers as an extra cost, renewable energies cause a noticeable price reduction in wholesale electricity markets. We analyse both effects for the case of the Spanish electricity market during 2010. In particular, we examine the level of FITs that makes savings and extra costs to be similar on an hourly basis. Results are obtained for a wide range of renewable generation scenarios. It is found that FITs with null extra costs for consumers are in the range of 50-80 $€ / \mathrm{MWh}$. Some of the sideeffects of a high penetration of renewable energy in the market are analysed in detail and discussed.
\end{abstract}

\section{Introduction}

Several reasons push governments to undertake goals for the deployment of Renewable Energy Sources (RES). Among them, RES avoid greenhouse gas emissions associated to conventional fossil fuel sources by promoting the use of local resources (which in turn increases energy sovereignty and improves the external balance of payment). In addition, renewable energies are a leading sector that allows countries to be at the cutting-edge of several technological and scientific fields. Along these lines, the European Commission adopted in 2007 the so-called EU climate and energy package, whose target (among others) is to provide $20 \%$ of European Union's energy consumption through RES by 2020 . To promote RES, economic support schemes are designed at the national level. The objective of economic incentives is twofold: first, to internalise the advantages of using RES into their cost, in such a way that private economic actors receive adequate investment signals. Second, to help industry achieve the economies of scale required for a largescale RES deployment.

In parallel, recent years have witnessed a transition in the electricity system of Western World countries from a governcontrolled economic framework towards a more market-oriented scenario. The implementation of electricity markets has introduced market mechanisms to set the electricity supply conditions (i.e. energy amounts and prices). The Spanish electricity market was created in 1997 through Act 54/1997 on the Electricity Sector, later developed through Royal Decree 2019/1997 [1]. At that time, the existing public support scheme for electricity from RES (RES-E) was adapted to this new framework through the implementation of feed-in-tariffs (FITs), which was specially successful in promoting wind energy [2]. Two important modifications were carried out in 2004 and 2007 [3,4] in order to modify FIT levels and to encourage RES-E producers to participate more actively in the electricity market. Such policies proved to be notably successful during the first decade of 2000 (see Ref. [5], and references therein) as Spain became one of the leaders in photovoltaic (PV) and wind energy deployment. In 2008, about half of the worldwide installed PV power was located in Spain [6], which in 2010 ranked first in the generation of wind power within the European Union [7].

FITs are paid by electricity consumers through the so-called regulated component of the electricity price. This component covers costs associated to national energy policies, costs associated to transmission networks, and extra costs related to insular electricity systems, among others. Notwithstanding, the continuous growth of RES-E has led to a noticeable increase of the regulated component (see Ref. [8]). As a consequence, FITs have been recently called into question, and the underlying benefits that motivated their implementation have been disregarded. Along these lines, successive royal decrees $[9,10]$ gradually reduced the level of FITs received by newly-installed RES-E plants, and retroactive measures affecting existing RES-E plants were also implemented. A few years later, FITs were finally cancelled for new facilities through Royal 
Decree 1/2012 [11], leading to an abrupt break of the installed renewable capacity trend in Spain. Royal Decree-Law 9/2013 [12] culminated this process by lowering the level of FITs retroactively for the whole of the renewable generators.

Nonetheless, and focussing merely on an economic standpoint, integrating RES-E reduces the electricity price in wholesale electricity markets. It hence translates to a decrease of the second component of the electricity price paid by consumers, the so-called market component. This effect is referred to as merit-order effect (MOE), and it represents a direct economical benefit derived from FIT schemes [13]. Several authors have analysed this effect for different case studies. Munksgaard and Morthorst [14] investigated the effect of wind power on the Danish power market, concluding that wind power allowed for a reduction in the market price of around 1-4€/MWh during 2004-2006. According to Jónsson et al. [15], day-ahead wind power forecasts are also likely to have an impact on the market price, affecting both the average level and the statistical distribution of the electricity price. For a deeper review of the impact of wind energy on electricity price, readers are referred to Gil et al. [16]. For the Spanish case, a reduction of about $4 \%$ of the electricity price between 2005 and 2010 associated to the use of renewable energies and cogeneration was reported in Gelabert et al. [17].

As the integration of RES-E entails the two mentioned effects (on the one hand, an increase of the regulated component and a decrease of the market component on the other), several questions arise: Which of the two effects is more relevant? What are the real costs of FITs for electricity consumers? Or, more specifically: What level of FITs can be paid to RES-E producers without increasing the final electricity price (regulated plus market components)? According to Sáenz-de Miera et al. [18], wind power generation in Spain yielded net cost savings of about $2146 \mathrm{M} €$ in the period 2005-2007. Similar figures were obtained by Gil et al. [16] between April 1, 2007 and December 31, 2010. In this line, Sensfuss et al. [19] found that renewable energies in Germany had led to a net transference of profits from producers to consumers. Likewise, Weigt [20] studied the impact of wind energy in Germany, concluding that, while FITs schemes entailed an extra cost of around 5.4-7€/ MWh between 2006 and 2007, these would have enabled a decrease in the market price of about $10 € / \mathrm{MWh}$ in the same period. In view of these aspects, the present work aims to delve into these questions; in particular, into the level of FITs drawn solely from savings in the day-ahead market (thus, without extra costs for consumers), which is explored on an hourly basis. This would eventually contribute to a better framing of the various FIT schemes developed during the last decade, as well as to the provision of new elements for debates on FIT policies. To this end, real data from the Iberian electricity market in 2010 are employed.

The article is organised as follows: Section 2 provides a brief description of the day-ahead market for the case of the Iberian electricity market. The MOE is introduced in Section 3, together with some approaches for its estimation reviewed in the literature. Section 4 describes the methodology adopted in this work. Results are presented and discussed in Section 5. The paper ends in Section 6 with some concluding remarks.

\section{The day-ahead market in the Iberian peninsula}

The Iberian Electricity Market, ${ }^{1}$ MIBEL, is organised as a sequence of several markets, namely the day-ahead market, six intra-day markets and the ancillary services market. Each market contributes to the market component of the electricity price,

\footnotetext{
${ }^{1}$ Integrated by the electricity markets of Portugal and Spain from 1 July 2007.
}

although the day-ahead market accounts for about $80-90 \%$ of this component [21]. Based on this, only the case of the day-ahead market is considered in this work.

The day-ahead market is executed once a day. This market allows participants to set their positions on an hourly basis for the following day. This is done by means of bids, which relate prices to amounts of energy that each participant is willing to produce/purchase for a certain hour. In order to determine the equilibrium between supply and demand, the labour of the Electricity Market Operator (OMIE) can be summarised as a twostaged procedure. First, a preliminary market equilibrium is obtained for every hour. With this purpose, generation bids are split in constant price segments and sorted in increasing order to build a preliminary version of the aggregated supply curve. Similarly, a preliminary version of the aggregated demand curve is built by sorting the segments of the purchase bids provided by retailers and wholesale consumers in decreasing order. The preliminary market equilibrium is defined by the intersection of both curves, which yields a preliminary market-clearing price and the associated generation plan (i.e. amounts of energy to be produce/purchased by each participant). Second, the final market equilibrium is computed by taking into account additional considerations. These are (i) market-splitting, which affects the aggregated demand curve, and (ii) complex conditions, which affects the aggregated supply curve.

(i) Market-splitting takes place when the preliminary equilibrium is such that the amount of electricity to be transferred between Portugal and Spain exceeds interconnection capacity. In this case, the market equilibrium is computed separately for each country. In practice, the maximum exchange capacity is considered as an additional demand bid in the exporting country, resulting in a shift of the aggregated demand curve.

(ii) Complex conditions are provided by some producers in order to specify additional requirements that can only be checked by considering jointly the market results obtained for several hours. These conditions can be either technical (for instance, to limit the resulting power output gradient of a power plant between two consecutive hours to a certain maximum) or economical (to condition the switch-on of the power plant to a minimum revenue threshold obtained throughout the day). In practice, taking complex conditions into account leads to the removal of some generation bids, in such a way that the aggregated supply curve becomes steeper.

Once these requirements have been taken into consideration, the new pair of aggregated curves provides the final market equilibrium, namely the market-clearing price, the amount of energy to be traded, and the related generation plan for the considered hour. For further details on the MIBEL market, readers are referred to MIBEL Regulatory Council [22].

In order to illustrate these notions, Fig. 1 depicts the aggregated curves of the day-ahead market for the 21st hour on 29 January, 2010. Dashed lines are employed to illustrate the preliminary pair of curves and solid lines represent the final curves after considering market-splitting and complex conditions. In particular, the shift to the right of the demand curve reflects a market-splitting situation, Spain being the exporting country in this case. The square marks the final market equilibrium situation. As can be seen, the final market-clearing price differs substantially from the price at the intersection of the preliminary curves, while the amount of energy to be traded remains practically unchanged owing to demand inelasticity. It is also worth noting that the preliminary pair of aggregated curves contain all the bids provided by the participants, 


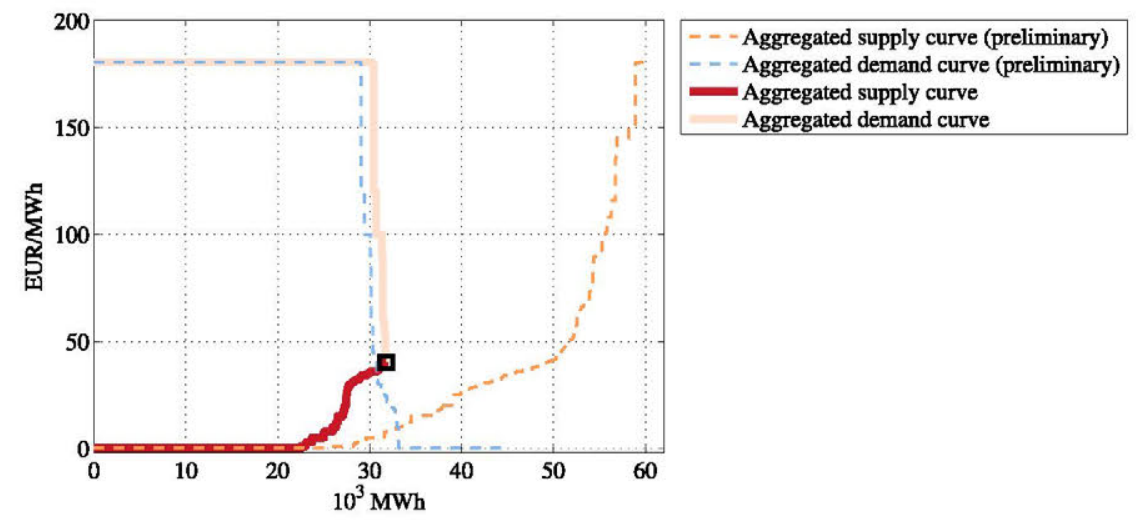

Fig. 1. Aggregated curves of the day-ahead market for the 21 st hour on 29 January, 2010.

whereas the final version of the curves are only computed up to the market equilibrium point.

Finally, it should be remarked that the day-ahead market is a uniform-price auction, meaning that the price at which producers are paid and retailers purchase electricity is the same for all the participants and equal to the final market-clearing price. Under this framework, generators maximise their benefits by bidding their opportunity cost, as this allows them to maximise the likelihood of being selected for electricity supply without failing to cover their avoidable costs.

\section{The merit-order effect}

In this section, the impact of RES-E on the day-ahead electricity market is examined. In particular, we analyse the so-called meritorder effect (MOE), which relates the market-clearing price reduction owing to the integration of renewable energy. A brief review on MOE estimations (methodologies and results) is also provided.

As mentioned in Section 1, RES-E producers have been encouraged to participate in the market together with conventional generators. Those among RES-E producers who use a resource that cannot be accumulated (mainly wind and PV, which accounted for $18 \%$ of the energy consumption in 2010 [23]) are willing to sell every kilowatt-hour at the exact moment that it is generated. In other words, the opportunity cost for non-dispatchable energy sources is zero. Consequently, and considering the framework described in Section 2, their best chance to match the generated energy is to bid the expected generation at zero price, which gives them an advantage in the market with respect to non-zero marginal cost technologies. The counterpart of non-dispatchable technologies is that they need to skillfully forecast the expected generation some time in advance (around 14-38 $\mathrm{h}$ for the case of the day-ahead market in the MIBEL) in order to avoid penalties due to deviations from the scheduled energy. In addition, accurate forecasts substantially ease the labour of the Transmission System Operator (TSO), responsible for accommodating intermittent generation under reliable conditions. Actually, there have been recent situations with wind power providing more than $64 \%$ of the total consumption in Spain, which represents an important achievement of the Spanish TSO in managing intermittent generation, specially considering the relatively low interconnection capacity of this country.

As a direct consequence of the integration of renewable energies $^{2}$ into the market, a number of bids at null price are added to

\footnotetext{
${ }^{2}$ For the sake of simplicity, the term renewable energies is used hereafter to refer only to those RES-E sources with opportunity cost equal to zero (that is, PV, wind energy and run-of-the-river hydroelectricity)
}

conventional generation bids, in such a way that the aggregate supply curve shifts to the right, thus lowering the market-clearing price. Because all the producing units are rewarded at the marketclearing price, the aforementioned shift translates to a decrease of the market component (introduced in Section 1) of the electricity price and, therefore, into savings for electricity consumers. The market-clearing price reduction caused by the integration of renewable generation leads to the notion of the MOE. Fig. 2 schematically shows this effect. Scenario A represents a market situation where supply (offer A) and demand determine the market-clearing price $p_{A}(€ / \mathrm{MWh})$ and a total traded energy $e_{A}$ (MWh). The market cost associated to the generation of this amount of energy, $c_{A}(€)$, is given by the area $c_{A}=p_{A} \cdot e_{A}$. Now, considering a market situation in which a certain amount of renewable energy $\Delta e_{R E S}(\mathrm{MWh}$ ) is added (scenario $\mathrm{B}$ ), the aggregated supply curve shifts this quantity to the right. In this scenario, the new market-clearing price, traded energy and market cost are given by Refs. $p_{B}, e_{B}$, and $c_{B}=p_{B} \cdot e_{B}$, respectively. The idea behind the MOE is to reflect the savings derived from the integration of renewable generation in the market. Thus, the MOE is defined as follows:

$\mathrm{MOE}=c_{A}-c_{B}=p_{A} \cdot e_{A}-p_{B} \cdot e_{B}$.

As mentioned above, FITs for RES-E cause an increase of the price paid by electricity consumers through the regulated component. Assuming a single FIT level for all the RES-E, $p_{F I T}(€ / \mathrm{MWh}){ }^{3}$ the extra cost, referred to as $c_{F T T}$, associated to $\Delta e_{R E S}$ is given by:

$c_{F I T}=p_{F I T} \cdot \Delta e_{R E S}$

Now, by considering the ratio $r$ between the MOE and the extra cost,

$r=\frac{\mathrm{MOE}}{c_{F I T}}=\frac{p_{A} \cdot e_{A}-p_{B} \cdot e_{B}}{p_{F I T} \cdot \Delta e_{R E S}}$,

it is possible to evaluate the overall effect of renewable generators integrated for a specific hour, that is, whether including $\Delta e_{R E S}$ leads to net savings $(r>1)$ or extra costs $(r<1)$ for electricity consumers.

In order to illustrate these notions, Fig. 3 has been performed using real data for the 21st hour on 29 January, 2010. For

\footnotetext{
${ }^{3}$ It has been assumed that RES-E generators receive the market clearing price plus a premium, $p_{F T}$. In fact, most wind generators chose this scheme in 2010 , the other option being the reception of a fixed tariff regardless the outcome of the market. Nevertheless, assuming one or another scheme is irrelevant to the problem at hand.
} 


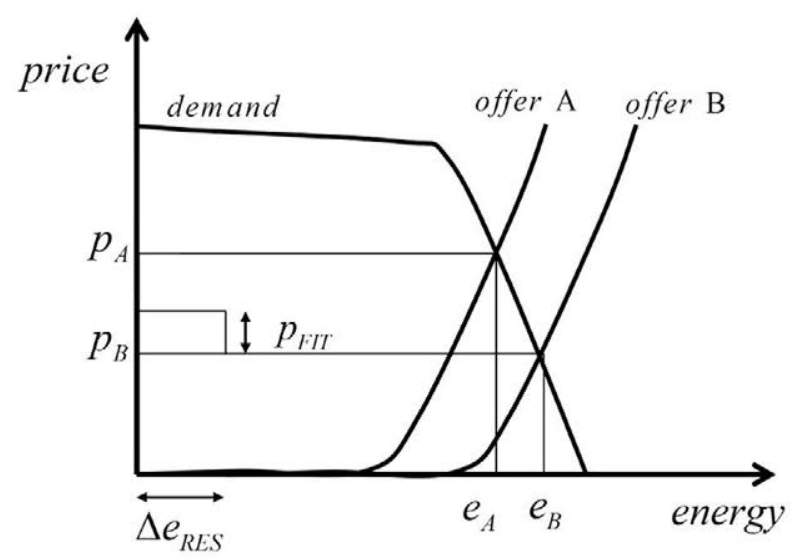

Fig. 2. Reduction of the market-clearing price, $p_{A}-p_{B}$, caused by the addition of a certain amount of renewable energy, $\Delta e_{\text {RES }}$.

convenience, the preliminary version of the aggregated curves has been employed as it gathers bids for both sides of the market equilibrium (problems related to the use of the final version of the curves are discussed in Section 4). Fig. 3 shows the scenarios described above, assuming a renewable generation of $10 \cdot 10^{3} \mathrm{MWh}$. The picture on the left represents Scenario $A$, where the square represents the total cost in the market for this hour, $c_{A}$. The plot on the right (Scenario $\mathrm{B}$ ) includes bids associated to renewable generation, leading to a noticeable decrease in the market-clearing price, hence a smaller square area associated to market costs, $c_{B}$. In this case, the extra cost due to subsidized renewable energy supply, $c_{F I T}$, is also represented. A constant premium of $p_{F I T}=50 € /$ MWh over the market price has been assumed for illustrative purposes (in practice, different technologies receive different premiums). Under these assumptions, the obtained ratio is $r=1.12$, meaning that savings owing to the MOE slightly overcome extra costs associated to FITs.

Assessing the exact amount of savings derived from the MOE throughout the year is not an easy task. So far, a number of approaches relying on different hypothesis have been presented. A first approach consists in calculating, for each hour of the year, the market-clearing price if no renewable generation at all had taken place. By comparing the computed price with the actual one and taking into account the total amount of traded energy, savings caused by the MOE can be estimated. This approach was adopted by

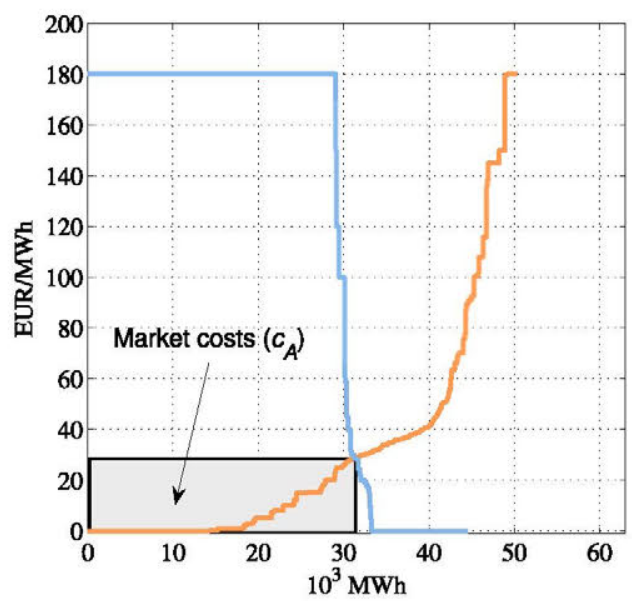

APPA [24], concluding that savings due to this effect in Spain between 2006 and 2010 exceeded subsidies received by renewable producers. Unfortunately, the analysis cannot be replicated and validated because a detailed description of the methodology is missing (in particular, it is not clear how the authors address some of the problems described in Section 4).

The approach followed by Sensfuss et al. [19] is radically different. The authors developed a simulation tool of the German electricity market by modelling the behaviour of different market participants. This tool was employed to predict market results under different scenarios (with and without renewable generation). The ratio $r$, defined in equation (3), was found to be in the range of $0.4-1$ between 2004 and 2006. It is important to remark that results concerning the German electricity market are not directly transferable to the Spanish case because of the dissimilarities between the two markets, such as differences in the penetration of renewable generation, among others. Nevertheless, this work illustrates that the MOE is not negligible in the German case.

In line with this work, Sáenz-de Miera et al. [18] proposed and validated a market simulation tool for the Spanish case. The study was limited to analyse the effect of wind power between 2005 and 2006. It was found that savings caused by the integration of wind energy were substantially higher than the subsidies received by this technology.

The approach of Gelabert et al. [17] is remarkably different as it is based on an ex-post statistical analysis of daily averages. This approach revealed a negative correlation between renewable generation and the averaged market-clearing price in Spain between 2007 and 2010. Moreover, results show that the related ratio $r$ (see equation (3)) was in the order of unity for the mentioned period, and close to the estimations obtained by APPA [24].

Fig. 4 depicts a comparative summary of the ratio $r$ obtained from some of the works reviewed. Despite differences in the methodology employed, the estimated savings due to the MOE were found to be in the same order of magnitude than the received subsidies. This result clearly suggests that, for the considered case studies, the extra cost paid by consumers for supporting RES-E deployment were roughly compensated by the savings experienced in the wholesale market.

\section{Methodology}

In this section, the methodology employed to analyse the MOE is described. Our approach is based in equation (3). This equation

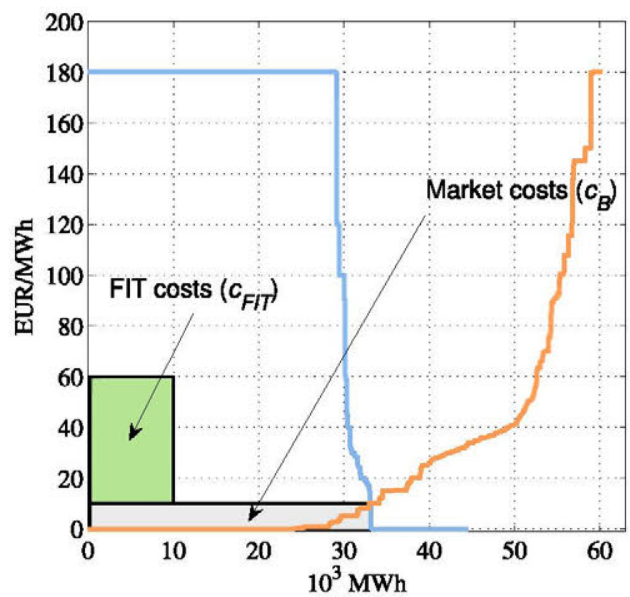

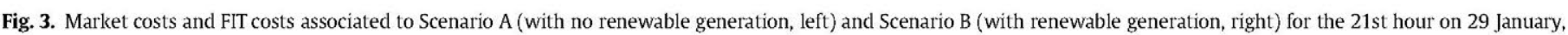
2010 . 


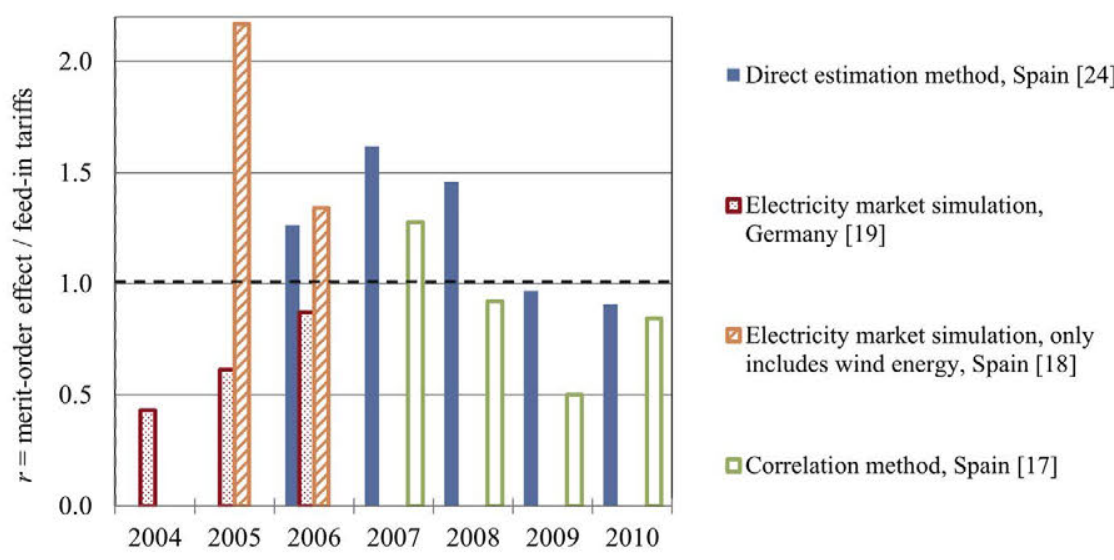

Fig. 4. Ratio between savings due to the MOE and extra costs due to FITs, $r$, computed on a yearly basis.

shows that the overall effect of renewable energies on the electricity price, given by the ratio $r$, depends on three factors: (i) the considered level of FITs, $p_{F T}$; (ii) the amount of integrated renewable generation, $\Delta e_{R E S}$; (iii) the aggregated curves, as they determine, for a specific hour, the dependency of the market equilibrium (market-clearing price and traded energy) on the amount of integrated renewable energy, that is, the relationships $p_{B}\left(\Delta e_{R E S}\right)$ and $e_{B}\left(\Delta e_{R E S}\right)$.

It is worth remarking that the FIT level that makes the ratio $r$ equal to one, denoted here by $p_{F T T}^{*}$, implies that the increase in renewable energy generation would have been obtained at zero cost for consumers, as the costs associated to FITs are exactly counteracted by savings in the wholesale market. Hence, by setting $r=1$, the following expression is obtained:

$p_{F I T}^{*}=\frac{p_{A} \cdot e_{A}-p_{B} \cdot e_{B}}{\Delta e_{R E S}}$

Thus, given the aggregated curves for a specific hour (i.e. the relationships $p_{B}\left(\Delta e_{R E S}\right)$ and $e_{B}\left(\Delta e_{R E S}\right)$ ), equation (4) provides $p_{F T}^{*}$ uniquely as a function of $\Delta e_{R E S}$, that is, $p_{F T T}^{*}\left(\Delta e_{R E S}\right)$.

Based on the above, our objective here is to analyse the relationship between $p_{F T}^{*}$ and $\Delta e_{R E S}$ for a wide range on renewable generation scenarios. With this purpose, real data from the MIBEL are employed. Let us consider the aggregated curves for a specific hour (see Fig. 1). A first question relates the pair of curves to be employed in the analysis, as two options are available: The preliminary and the final version of the aggregated curves. To our knowledge, the use of the former is not recommended because the preliminary curves do not reflect some features involved in the price determination, such as complex conditions and marketsplitting. In particular, as explained in Section 2, considering complex conditions increases the slope of the aggregated supply curve. Thus, the preliminary version of the aggregated supply curve actually embodies a non-realistic sensitivity of the market-clearing price $p_{B}$ with respect to $\Delta e_{R E S}$. Based on this, the relationships $p_{B}\left(\Delta e_{R E S}\right)$ and $e_{B}\left(\Delta e_{R E S}\right)$ are to be obtained from the final version of the aggregated curves provided by the market operator.

A second question relates the procedure to implement the different renewable generation scenarios. Two strategies can be adopted:

(a) A first option consists in removing those bids provided by wind power and PV generators from the aggregated generation curve. In this case, the supply curve shifts to the left and higher market-clearing prices are obtained. Consequently, the analysis is mainly focused on the impact of the existing renewable facilities on the market, and the obtained $p_{F T}^{*}$ values can be employed as a reference for comparing and discussing the FITs established by the legislation in force at that time.

(b) Conversely, the second option is to consider the addition of virtual bids at zero price, in such a way that the supply curve shifts to the right. In this case, the analysis is rather oriented to assess the impact of additional RES-E capacity on the market, giving insights on what level of FITs had been reasonable at that moment for those potential new generators.

In order to choose between the strategies described above, the following two considerations should be made. First, for the case of the approach described in (a), the different renewable generation scenarios arise from considering negative $\Delta e_{R E S}$ values, from zero to a certain (negative) value, this value reflecting the total energy offered by wind and PV generators for the hour under analysis. The drawback of this approach is that there is no available information on what bids at zero price were made by these technologies. Indeed, while each conventional power unit (gas, carbon and nuclear) operates in the MIBEL as a single market participant, power units included in the so-called Special Regime ${ }^{4}$ are allowed to bid jointly as a single market participant, in such a way that a single bid includes the expected generation of different technologies. Consequently, it is virtually impossible to determine the aforementioned total energy offered by wind and PV generators from the information provided by the market operator.

Second, as mentioned in Section 2, it is important to note that the final aggregated curves are only obtained up to the point where the market equilibrium is reached (see Fig. 1). Hence, no further information is provided beyond this point. In light of this, it is clear that shifting the final supply curve either to the left or to the right makes it impossible to obtain a matching price. Under strategy (a) (the aggregated supply curve shifts to the left) this drawback could be overcome by extending the supply curve with the initial version of this curve (for which the declared complex conditions have not been considered). In contrast, computing the market equilibrium under strategy $(b)$ would require the final aggregated demand curve to be extended with the preliminary one. In our opinion, the latter option is more appealing since the single difference (if any) between the preliminary and the final aggregated demand curve is

\footnotetext{
${ }^{4}$ Special Regime includes electricity generation from any renewable source (excluding conventional hydro), cogeneration and wastes.
} 
the shift due to market-splitting, which can be easily identified and accounted for from the available data. In light of this, the strategy described in $(b)$ has been adopted.

To summarize, the main features of the proposed approach are the following:

- Our approach is devoted to obtain the FIT level $p_{F I T}^{*}$ that compensates the associated extra costs with the savings obtained in the day-ahead market. This is done for different renewable generation scenarios (i.e. different values for $\Delta e_{R E S}$ ).

- The different renewable generation scenarios are implemented by adding bids at zero price. Consequently, the analysis focuses on the impact of additional RES-E installations on the market results.

- The analysis makes use of real data provided by OMIE. A first consequence is that results are obtained on an hourly basis, which keeps pace with the market running; this approach allows for a more refined analysis than those relying on daily averaged data [17].

- A second consequence of the use of real data is a higher reliability of the results. According to Bode [25], estimating the impact of renewable energies on the market results is very sensitive to the slope of the employed curves. Thus, the use of real curves is deemed to be preferable to market simulationbased tools $[18,19]$.

\section{Results and discussion}

In order to estimate the FIT level with zero cost for consumers, $p_{F T}^{*}$, data corresponding to year 2010 were employed. This dataset is available at the web page of the market operator [21] and it contains all the bids provided by every market participant for every hour of the year. It is worth noting that a modification was introduced on 1st June as bids, so far provided in $€ \mathrm{c} / \mathrm{kWh}$, started to be provided in $€ / M W h$. The dataset was corrected accordingly.

Following the methodology described in Section 4, the new market equilibrium (that is, market-clearing price, $p_{B}$, and traded energy, $e_{B}$ ) was obtained for each hour of the year and for different renewable generation scenarios $\left(\Delta e_{R E S}\right)$. In particular, $\Delta e_{R E S}$ ranged from $10 \mathrm{MW}$ to $10 \cdot 10^{3} \mathrm{MW}$ in steps of $10 \mathrm{MW}$. Results were collected in functions referred to as $p_{B}\left(\Delta e_{R E S}, H\right)$ and $e_{B}\left(\Delta e_{R E S}, H\right)$, where $H$ represents a specific hour of the year, ranging from 1 to 8760. Thus, these functions provide a comprehensive mapping of the impact of any additional bid at zero price on the market results throughout the year. It is to be noted that the original market equilibrium (i.e. initial market-clearing price, $p_{A}$, and traded energy, $\left.e_{A}\right)$ is given by Refs. $p_{B}(0, H)$ and $e_{B}(0, H)$.

As an example, Fig. 5 shows functions $p_{B}\left(\Delta e_{R E S}, H\right)$ (left) and $e_{B}\left(\Delta e_{R E S}, H\right)$ (right) for three specific hours: $H=797$ (H5 on $3 / \mathrm{Feb}$, corresponding to off-peak hour), $H=4774$ (H23 on 18/Jul, corresponding to peak hour) and $H=7062$ (H7 on 22/Oct). Focussing on the plot on the left, the curve associated to $3 / \mathrm{Feb}-\mathrm{H} 5$ shows a relatively low initial market-clearing price $\left(p_{B}(0,797)=12.13 € /\right.$ $\mathrm{MWh}$ ); as expected, this price decreases for increasing $\Delta e_{R E S}$ values, reaching zero for $\Delta e_{R E S}=3840 \mathrm{MW}$; beyond this point, following generation scenarios provide systematically null market-clearing price, while traded energy increases proportionally to $\Delta e_{R E S}$ (see figure on the right), meaning that any amount of extra energy at zero price is integrated into the system. Conversely, the curve related to $18 / \mathrm{Jul}, \mathrm{H} 23$ corresponds to a situation with a very high initial market-clearing price $\left(p_{B}(0,4774)=70.01 € / \mathrm{MWh}\right)$. In this situation, null price is not reached even for the maximum $\Delta e_{R E S}$ value considered. It can also be noted that, due to demand inelasticity, the traded energy remains practically unchanged. Finally, the curve related to 22/Oct, $\mathrm{H} 7$ shows an intermediate situation, reaching a market price close to zero for $\Delta e_{R E S}=10 \cdot 10^{3} \mathrm{MWh}$, the maximum value considered in the study.

Although Fig. 5 merely represents three of the 8760 curves obtained for 2010, it may be observed that the effect of RES-E on the market results may become highly dependent on the specific hour under consideration. This suggests that important features of the results obtained throughout the year might be hidden if averaged values are employed. For this reason, in an effort to provide a compact and efficient view of the raw maps $p_{B}\left(\Delta e_{R E S}, H\right)$ and $e_{B}\left(\Delta e_{R E S}, H\right)$, the following approach has been adopted. Let us consider a certain renewable generation scenario $\Delta e_{R E S}=\Delta e_{0}$ with $0 \leq \Delta e_{0} \leq 10 \cdot 10^{3} \mathrm{MW}$. The 8760 samples contained in Ref. $p_{B}\left(\Delta e_{0}, H\right)$ can be employed to characterise the statistical distribution of the impact of a constant bid $\Delta e_{0}$ at zero price on $p_{B}$ throughout the year. This statistical distribution is to be characterised by means of percentiles, P1, P2, ..., P100. Then, by considering the statistical distributions obtained for the different scenarios, the aforementioned percentiles become a function of $\Delta e_{R E S}$. These relationships are illustrated in Fig. 6 (left). On the right, a similar picture is obtained for the case of $e_{B}\left(\Delta e_{R E S}, H\right)$.

Finally, and considering equation (4), map $p_{F T}^{*}\left(\Delta e_{R E S} ; H\right)$ was obtained. A representation of this map in terms of percentiles is shown in Fig. 7. Additionally, the histograms related to two specific scenarios, $p_{F T}^{*}(2000 ; H)$ and $p_{F T}^{*}(8000 ; H)$, are shown on the right. These histograms show a relatively high number of hours with $p_{F T T}^{*}=0$. A detailed analysis revealed that these cases are mostly related to situations with null market-clearing price for the original scenario $\left(\Delta e_{R E S}=0\right)$. Indeed, having $p_{A}=0$ translates into $p_{B}=0$ regardless the $\Delta e_{R E S}$ value considered, zeroing the numerator in the right side of equation (4).

\subsection{Further discussion}

Fig. 7 embodies crucial information to address the main question of this work. This figure depicts, for the case of the Spanish electricity market in 2010, the rewards that could be assigned to newly-installed RES-E plants without incurring in extra costs for consumers due to the MOE. The information is provided in terms of statistical distributions computed from hourly results and conditioned to a certain level of integrated renewable energy, $\Delta e_{R E S}$. As can be seen, the median of this reward evolves smoothly from $50 € /$ MWh to $80 € / M W h$ for the considered scenarios. For the $66 \%$ of the hours (the band between percentiles P17 and P83), the premium varies from 27 to $118 € / \mathrm{MWh}\left(\Delta e_{R E S}=1 \cdot 10^{3} \mathrm{MWh}\right)$ to $50-105 € /$ $\operatorname{MWh}\left(\Delta e_{R E S}=10 \cdot 10^{3} \mathrm{MWh}\right)$. In order to gain more insight, these figures need to be compared with FITs received by technologies included in the Special Regime during the same time period. Table 1 shows the averaged premium according to technology, together with the total generated energy (third column) and the generation averaged on an hourly basis (rightmost column). It is to be noted that only wind power, PV and run-of-the-river hydro bid systematically at zero price in the market.

It is possible to observe that, roughly speaking, most technologies received a premium in line with the most likely $p_{F I T}^{*}$ values obtained. This result is in good agreement with previous works stating that FIT extra cost and savings due to MOE are in the same range [17,24]. Consequently, and considering the interpretation of the adopted approach (see Section 4), this study supports the idea that FIT schemes could have been applied to a large amount of additional RES-E generation (up to $10 \cdot 10^{3}$ extra MWh per hour, and, in view of Fig. 7, probably more) without translating into extra costs for consumers. It is noted that the last scenario considered $\left(\Delta e_{R E S}=10 \cdot 10^{3} \mathrm{MWh}\right)$ represents duplicating the amount of energy 

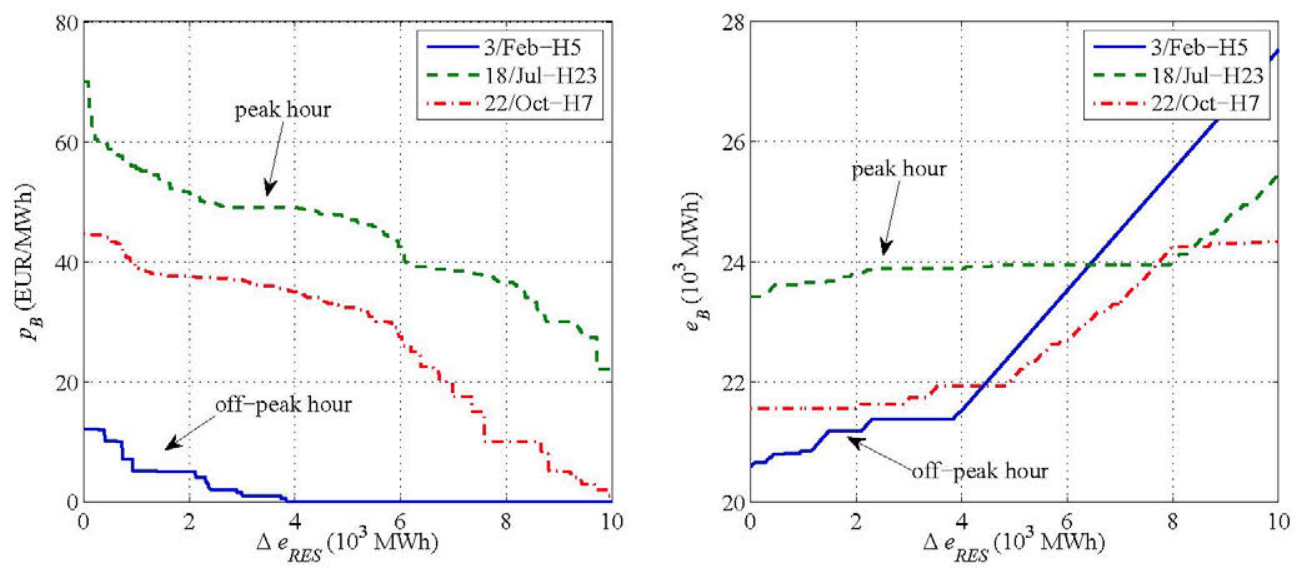

Fig. 5. New market-clearing price $p_{B}$ (left) and traded energy $e_{B}$ (right) as a function of the renewable generation scenario $\Delta e_{R E S}$ for three different hours in 2010 .
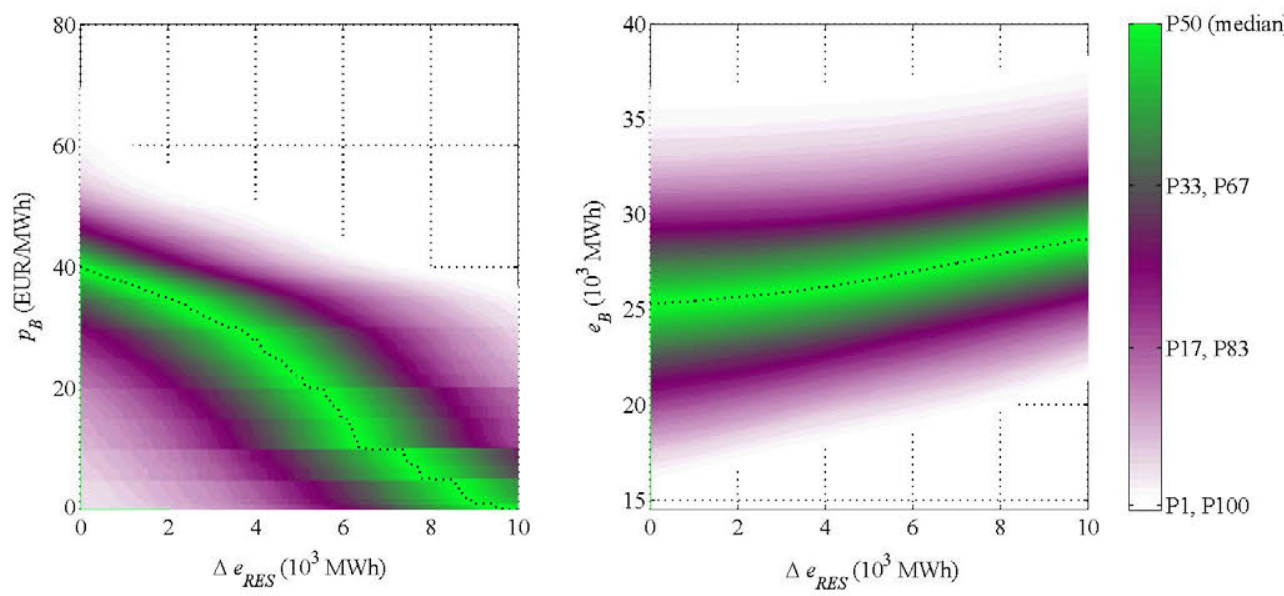

Fig. 6. Probability distribution (in terms of percentiles) of the new market-clearing price $p_{B}$ (left) and traded energy $e_{B}$ (right) conditioned to different renewable generation scenarios, $\Delta e_{R E S}$.

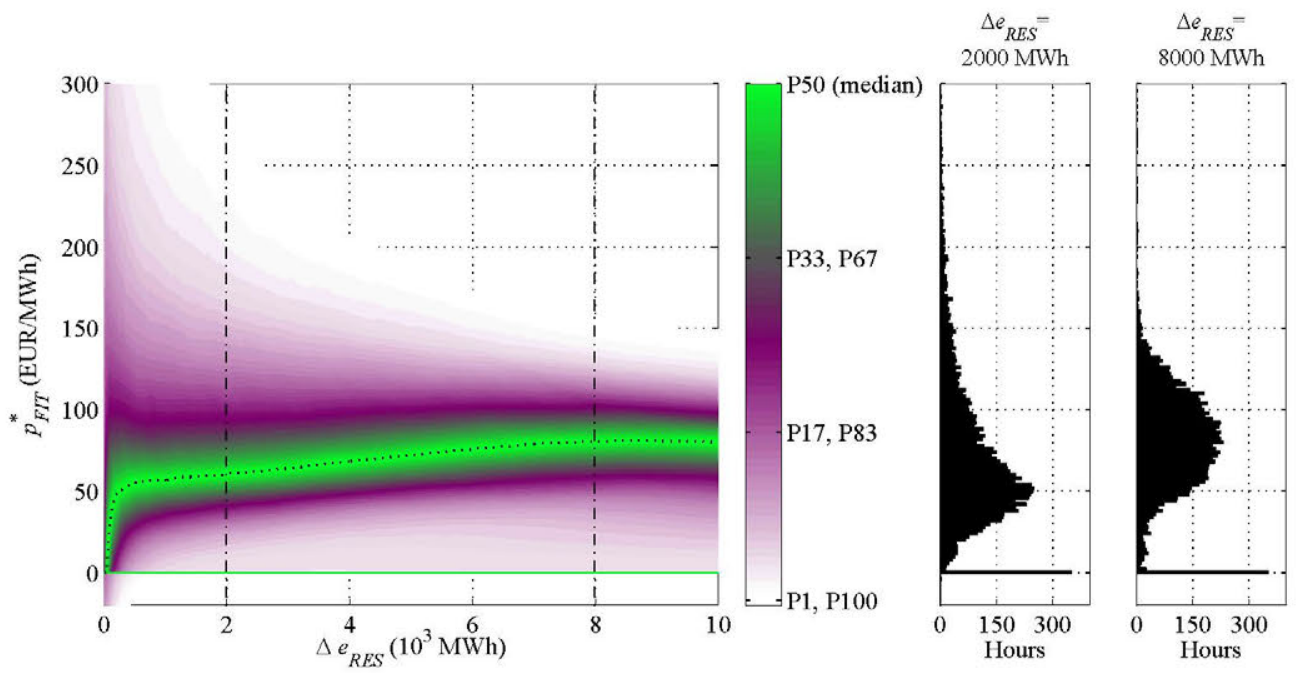

Fig. 7. Left, probability distribution (in terms of percentiles) of the cost-free FIT, $p_{F T T}^{*}$, conditioned to different renewable generation scenarios $\Delta e_{R E S}$. Right, histograms of $p_{H T}^{*}$, for two specific scenarios: $\Delta e_{R E S}=2000 \mathrm{MWh}$ and $\Delta e_{R E S}=8000 \mathrm{MWh}$. 
Table 1

Averaged premium and generated energy for every technology within the Special Regime during 2010. Source: [26].

\begin{tabular}{|c|c|c|c|}
\hline Technology & Average premium $(€ / \mathrm{MWh})$ & Total energy (TWh) & Mean hourly energy $\left(10^{3} \mathrm{MWh}\right)$ \\
\hline Cogeneration & 56.40 & 23.68 & 2.70 \\
\hline PV & 414.26 & 6.41 & 0.73 \\
\hline Solar thermal & 264.07 & 0.70 & 0.08 \\
\hline Wind & 45.57 & 43.14 & 4.92 \\
\hline Hydro & 44.04 & 6.73 & 0.77 \\
\hline Biomass & 77.51 & 3.14 & 0.36 \\
\hline Waste & 29.78 & 3.12 & 0.36 \\
\hline Waste treatment & 81.71 & 4.29 & 0.49 \\
\hline Total & 78.12 & 91.25 & 10.42 \\
\hline
\end{tabular}

coming from the Special Regime for year 2010 (see Table 1, accumulated value of the rightmost column). The single exception to this argument seems to be solar technology (PV and solar thermal), whose average premium exceeded by large the results obtained. It should be remarked here that the high FIT levels for these technologies were designed in a context of very high costs of the installed MWp. In fact, one of the main objectives of FITs was to help the scale up of PV manufacturing and installation to obtain the resulting costs reduction. However, and focussing on PV, this situation has radically changed in the past few years as the levelized cost of electricity (LCOE) is quickly approaching $50 € / \mathrm{MWh}$ [27]. The striking decrease recently experienced in costs actually enables PV to have the potential to reach grid parity for households [28], making FITs schemes (and probably current electricity market designs) obsolete in a near future [29].

Thus, if there is still room for adding new RES-E capacity under FIT schemes without incurring in extra costs for consumers, the next question is about who would be bearing the associated economical costs. At this point, it should be clear that the MOE basically represents an income transfer mechanism from nonrewarded technologies (mostly, traditional thermal power generation) towards renewable energies with null opportunity costs. As shown in Fig. 6 (left), the MOE triggers an important decrease of the market-clearing price in such a way that the median of the market price becomes practically null for the last scenarios considered ( $\Delta e_{R E S}$ close to $10 \cdot 10^{3} \mathrm{MWh}$ ). In parallel, renewable energies causing this effect would receive a remuneration of $p_{B}+p_{F T T}^{*}$. The statistical distribution of this remuneration is depicted in Fig. 8 for the different scenarios considered. Interestingly, a remuneration roughly constant of around $100 € / \mathrm{MWh}$ can be observed.

The effects of the income transfer mechanism illustrated in Fig. 6 (left) and 8 deserve several comments. First, null clearingmarket prices should come as no surprise since spot markets are intended to reveal marginal costs, namely, the marginal cost of the most expensive technology required for covering the aggregated demand. Under this economical framework, investment costs associated to a certain generation plant are assumed to be recovered in the long-term through the gap between the marketclearing price and the own marginal costs. Herein lies the key point of marginal markets, which tend to penalise investments on technologies with high initial costs and low (if any) marginal costs, such as nuclear and renewable energies. Therefore, in a foreseeable large-scale renewable energy integration scenario, FIT schemes has the potential to balance this situation in such a way that the electricity market, so far conceived as a mechanism for covering marginal costs, becomes progressively a stable framework that also covers initial costs as well.

Second, concerning non-rewarded technologies, some authors have pointed that null market prices might provide incorrect investment signals on back-up power, risking the reliability of the

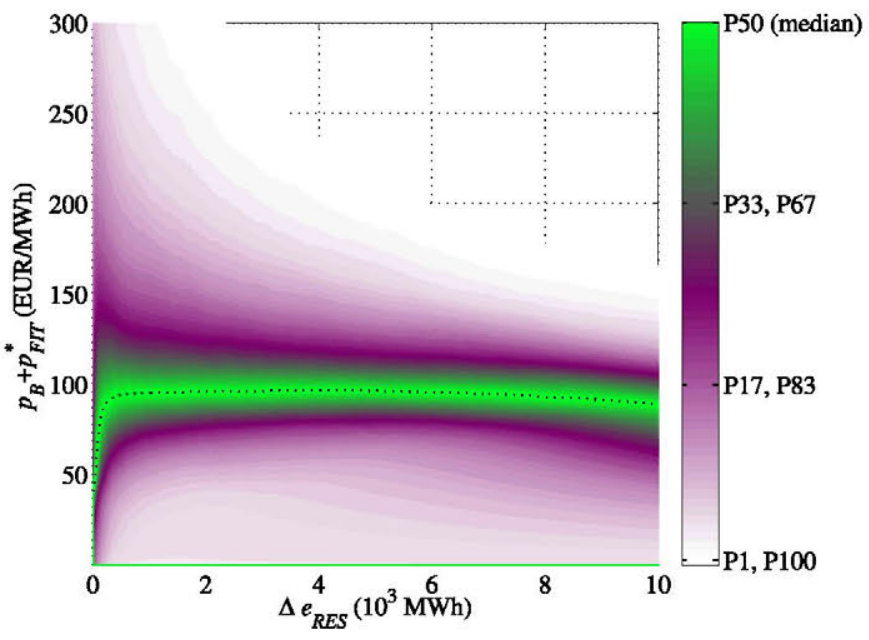

Fig. 8. Probability distribution (in terms of percentiles) of the incomes received by RES-E generators (new market clearing price + cost-free FIT, $p_{B}+p_{F I T}^{*}$ ) conditioned to different renewable generation scenarios, $\Delta e_{R E S}$

electricity supply in the mid/long-term [30]. However, it is important to keep in mind that electricity markets usually enable additional remuneration mechanisms for technologies providing ancillary services and base-load generation. Specifically, capacity payments are usually designed to remunerate available capacity regardless of whether it is required for generation or not. This mechanism has also been employed as a means to allow traditional thermal facilities (such as nuclear, carbon and gas) to recover their initial costs [31]. For the Spanish case, capacity payments in 2010 evaluated on a monthly basis represented between $6.8 \%$ and $16.2 \%$ of the market clearing prices [21]. Whether or not capacity payments ought to be revised in a context of high renewable penetration is a question to be carefully addressed in the future. This exercise ought to be based on a thoroughly analysis of the overall remunerations received by traditional facilities throughout the different economical frameworks operating in Spain during the last decades, as regulatory changes are likely to have rendered windfall profits to most of these facilities [32].

\section{Concluding remarks}

In this work, the impact of renewable energies on the Spanish electricity market has been analysed. In particular, the balance between extra costs associated to feed-in-tariffs (FITs) and savings due to the merit-order effect (MOE) was explored on an hourly basis for year 2010. Results suggested that there is room for integrating technologies with null opportunity cost (namely, wind power and PV) under FIT schemes without incurring in extra costs 
for consumers. Specifically, FITs drawn solely from savings in the day-ahead market were found to be in the range of 50-80 $€ / M W h$. In parallel, depending on the considered renewable generation scenario, a substantial drop in electricity price may be observed.

Results also suggested that the path towards large-scale renewable energy deployment is not a problem with economic constraints. Conversely, the increasing share of technologies with high investment cost and low marginal cost in the generation mix calls for specific-case modifications in the economic framework, which do not necessarily translate into higher electricity costs for consumers. As observed, the sole implementation of appropriate FITs could help create a stable remuneration framework (of around $100 € / \mathrm{MWh}$ ) for the mentioned technologies, at least for the considered generation scenarios (up to doubling the energy generated by the Special Regime in Spain in 2010).

Perhaps, the main limitation of this study is the assumption that the supply bids remain unchanged under the considered renewable generation scenarios. A priori, a different behaviour of the generation units in the market cannot be expected as long as each generation bid is intended to convey the participant opportunity cost, which depends uniquely on the involved technology and not on the other participant positions. However, for the case of the Spanish electricity market, a reduced number of big firms dominate both the wholesale and the retailer market. In this context, according to Gelabert et al. [17], the hypothesis of power market cannot be discarded. Another mechanism that could modify the aggregated supply curve under the different considered scenarios is that of complex conditions. As explained in Section 2, complex conditions have the potential to moderate the decrease in the market-clearing price, as some bids are subjected to be removed from the aggregated supply curve in order to meet additional requirements. The use of the final version of the aggregated curves allowed us to account only for those complex conditions activated for the original scenario $\left(\Delta e_{R E S}=0\right)$. In order to account for complex conditions that might be activated for the rest of the scenarios, an extended dataset fully describing complex conditions for every hour is required. Further research is therefore needed to quantify the impact of complex conditions on the results obtained in this work. Likewise, the hypothesis of constant line capacity with neighbouring countries could be relaxed in further studios, and more emphasis could be placed on a evolving renewable mix, since new PV capacity is likely to impact the market more than wind energy due to higher market prices during daylight hours.

One last remark needs to be done. FITs were analysed here on the basis of constant electricity cost, this being given by the addition of the market costs plus extra costs due to incentives. However, in line with Burgos-Payán et al. [8], renewable energy deployment entails additional benefits to be considered by policymakers. Firstly, the avoided tons of greenhouse gas emissions directly translates into savings due to $\mathrm{CO}_{2}$ emission rights that are no longer purchased. Secondly, the decrease in the use of fossil fuels for electricity generation involves significant savings and a major improvement in the exterior balance of payments. Finally, promoting renewable facilities in Spain entail additional benefits of the utmost importance, even when they cannot be easily quantified in economic terms, such as the deceleration of climate change (thus a cost reduction of the necessary mechanisms for mitigation and adaptation claimed by the Intergovernmental Panel on Climate Change [33]) or the increase in energy sovereignty. This last may be particularly significant in a scenario of escalating fossil fuel prices and geopolitical issues affecting countries from which Spain imports more than $80 \%$ of the energy that it consumes today.

\section{References}

[1] MINER (Ministerio de Industria y Energía). Real Decreto 2019/1997, de 26 de diciembre, por el que se organiza y regula el mercado de producción de energía eléctrica. Spain's Off J BOE December 27, 1997;(310). 1997.

[2] del Río-González P, Miguel AG. An integrated assessment of the feed-in tariff system in Spain. Energy Policy 2007;35(2):994-1012. http://dx.doi.org/ 10.1016/j.enpol.2006.01.014.

[3] MIEC (Ministerio de Economía). Real Decreto 436/2004, de 12 de marzo, por el que se establece la metodología para la actualización y sistematización del régimen jurídico y económico de la actividad de producción de energía eléctrica en régimen especial. Spain's Off J BOE March 27, 2004;(75). 2004.

[4] MITYC (Ministerio de Industria, Turismo y Comercio). Real Decreto 661/2007, de 25 de mayo, por el que se regula la actividad de producción de energía eléctrica en régimen especial. Spain's Off J BOE May 26, 2007;(126). 2007.

[5] del Río-González P. Ten years of renewable electricity policies in Spain: an analysis of successive feed-in tariff reforms. Energy Policy 2008;36(8): 2917-29. http://dx.doi.org/10.1016/j.enpol.2008.03.025.

[6] ASIF (Asociación de la Industria Fotovoltaica). Hacia la consolidación de la energía fotovoltaica en España. Tech. Rep.. 2009. Available at: http://www. erasolar.es/pdf\%27s/ASIF Informe anual 2009.pdf

[7] EurObservER. Wind power barometer. Tech. Rep.. 2012. Available at: http:// www.eurobserv-er.org/press.asp

[8] Burgos-Payán M, Roldán-Fernández JM, Trigo-García AL, Bermúdez-Ríos JM, Riquelme-Santos JM. Costs and benefits of the renewable production of electricity in Spain. Energy Policy 2013;56(0):259-70. http://dx.doi.org/ 10.1016/j.enpol.2012.12.047.

[9] MITYC (Ministerio de Industria, Turismo y Comercio). Real Decreto 1578/2008, de 26 de septiembre, de retribución de la actividad de producción de energía eléctrica mediante tecnología solar fotovoltaica para instalaciones posteriores a la fecha límite de mantenimiento de la retribución del Real Decreto 661/ 2007, de 25 de mayo, para dicha tecnología. Spain's Off J BOE September 27, 2008;(234). 2008.

[10] JE (Jefatura del Estado). Real Decreto-ley 14/2010, de 23 de diciembre, por el que se establecen medidas urgentes para la corrección del déficit tarifario del sector eléctrico. Spain's Off J BOE December 24, 2010;(312). 2010.

[11] JE (Jefatura del Estado). Real Decreto-ley 1/2012, de 27 de enero, por el que se procede a la suspensión de los procedimientos de preasignación de retribución y a la supresión de los incentivos económicos para nuevas instalaciones de producción de energía eléctrica a partir de cogeneración, fuentes de energía renovables y residuos. Spain's Off J BOE January 28, 2012;(24). 2012.

[12] JE (Jefatura del Estado). Real Decreto-ley $9 / 2013$, de 12 de julio, por el que se adoptan medidas urgentes para garantizar la estabilidad financiera del sistema eléctrico. Spain's Off J BOE July 13, 2013;(167). 2013.

[13] EWEA (European Wind Energy Association). Wind energy and electricity prices. exploring the merit order effect. Tech. Rep.. 2010. Available at: http:// www.ewea.org/fileadmin/ewea_documents/documents/publications/reports/ MeritOrder.pdf

[14] Munksgaard J, Morthorst PE. Wind power in the Danish liberalised power market - policy measures, price impact and investor incentives. Energy Policy 2008;36(10):3940-7. http://dx.doi.org/10.1016/j.enpol.2008.07.024.

[15] Jónsson T, Pinson P, Madsen $H$. On the market impact of wind energy forecasts. Energy Econ 2010;32(2):313-20. http://dx.doi.org/10.1016/ j.eneco.2009.10.018.

[16] Gil HA, Gomez-Quiles C, Riquelme J. Large-scale wind power integration and wholesale electricity trading benefits: estimation via an ex post approach.

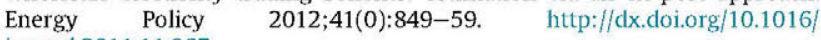
j.enpol.2011.11.067.

[17] Gelabert L, Labandeira X, Linares P. An ex-post analysis of the effect of renewables and cogeneration on Spanish electricity prices. Energy Econ 2011;33:S59-65. http://dx.doi.org/10.1016/j.eneco.2011.07.027. Supplement $1(0)$ Supplemental issue: Fourth Atlantic Workshop in energy and Environmental economics.

[18] Sáenz-de Miera G, del Río-González P, Vizcaíno I. Analysing the impact of renewable electricity support schemes on power prices: the case of wind electricity in Spain. Energy Policy 2008;36(9):3345-59. http://dx.doi.org/ 10.1016/j.enpol.2008.04.022.

[19] Sensfuss F, Ragwitz M, Genoese M. The merit-order effect: a detailed analysis of the price effect of renewable electricity generation on spot market prices in Germany. Energy Policy 2008;36(8):3086-94. http://dx.doi.org/10.1016/ j.enpol.2008.03.035.

[20] Weigt H. Germany's wind energy: the potential for fossil capacity replacement and cost saving. Appl Energy 2009;86(10):1857-63. http://dx.doi.org/ 10.1016/j.apenergy.2008.11.031.

[21] OMIE web page. http://www.omie.es/. [accessed date 16.05.14].

[22] MIBEL Regulatory Council. Description of the operation of the mibel. Tech. Rep.. 2009. Available at: http://www.erse.pt/eng/electricity/MIBEL/ Documents/Description_operation_MIBEL.pdf

[23] REE (Red Eléctrica de España). El sistema eléctrico español 2010. Tech. Rep.. 2010. Available at: http://www.ree.es/es/publicaciones/sistema-electricoespanol

[24] APPA (Asociación de Productores de Energías Renovables). Estudio del impacto macroeconómico de las energías renovables en España - año 2010. 
Tech. Rep.. 2010. Available at: http://www.appa.es/descargas/APPA2010web. pdf

[25] Bode S. On the impact of renewable energy support schemes on power prices. Tech. Rep. Hamburg Institute of International Economics; 2006

[26] CNE (Comisión Nacional de la Energía). Información Estadística sobre las Ventas de Energía del Régimen Especial. 2011. Available at: http://www.cne. es/cne/Publicaciones?id_nodo $=143 \&$ accion $=1 \&$ soloUltimo $=$ si\&sIdCat $=10 \&$.

[27] Bolinger M, Weaver S. Utility-scale solar 2012: an empirical analysis of project cost, performance, and pricing trends in the United States. Tech. Rep. Lawerence Berkeley National Laboratory; 2013. Available at: http://emp.lbl.gov/ sites/all/files/lbnl-6408e_0.pdf

[28] Breyer C. Global overview on grid-parity. Prog Photovoltaics 2013;21(1): 121-36. http://dx.doi.org/10.1002/pip.1254.

[29] Schleicher-Tappeser R. How renewables will change electricity markets in the next five years. Energy Policy 2012;48(0):64-75. http://dx.doi.org/10.1016 j.enpol.2012.04.042.
[30] Moreno F, Martínez-Val JM. Collateral effects of renewable energies deployment in Spain: Impact on thermal power plants performance and management. Energy Policy 2011;39(10):6561-74. http://dx.doi.org/10.1016/ j.enpol.2011.07.061.

[31] Chuang A, Fu F. Capacity payments and the pricing of reliability in competitive generation markets. In: System sciences, 2000. Proceedings of the 33rd annual Hawaii international conference on; 2000. p. 8. http://dx.doi.org/10.1109/ HICSS.2000.926762.

[32] Fabra N, Fabra J. El diseño de mercado para el sector eléctrico español. Papeles Econ española 2009;121:141-58.

[33] IPCC (Intergovernmental Panel on Climate Change). Climate change 2007 mitigation of climate change. Working Group III contribution to the Fourth Assessment Report of the Intergovernmental Panel on Climate Change. Tech. Rep.. 2007. Available at: http://www.ipcc.ch/publications_and_data/ar4/wg3/ en/contents.html 